\title{
Impact of a radio-frequency identification system and information interchange on clearance processes for cargo at border posts
}

\begin{abstract}
Authors:
Ernest Bhero

Alwyn Hoffman²

Kabanda Lusanga ${ }^{2}$

Arno de Coning ${ }^{2}$

Affiliations:

${ }^{1}$ Discipline of Electrical,

Electronic and Computer

Engineering, University of

KwaZulu-Natal, South Africa

${ }^{2}$ School of Electrical,

Electronic and Computer

Engineering, North-West

University, South Africa
\end{abstract}

Correspondence to:

Ernest Bhero

Email:

bhero@ukzn.ac.za

Postal address:

PO Box 51442, Durban 4062 ,

South Africa

Dates:

Received: 02 Apr. 2015

Accepted: 20 July 2015

Published: 04 Nov. 2015

How to cite this article: Bhero, E., Hoffman, A., Lusanga, K. \& De Coning, A., 2015, 'Impact of a radiofrequency identification system and information interchange on clearance processes for cargo at border posts', Journal of Transport and Supply Chain Management 9(1), Art. \#181, 14 pages. http://dx.doi. org/10.4102/jtscm.v9i1.181

\section{Copyright:}

(C) 2015. The Authors.

Licensee: AOSIS

OpenJournals. This work is

licensed under the Creative

Commons Attribution

License.

\section{Read online:}

Background: Improved operational efficiency is important to role players in cross-border logistics and trade corridors. Cargo owners and cargo forwarders have been particularly concerned about long delays in the processing and clearing of cargo at border posts. Field studies suggest that these delays are due to a combination of factors, such as a lack of optimum system configurations and non-optimised human-dependent operations, which make the operations prone to corruption and other malpractices.

Objectives: This article presents possible strategies for improving some of the operations in this sector. The research hinges on two key questions: (1) what is the impact of information interchange between stakeholders on the cargo transit time and (2) how will cargo transit time be impacted upon by automatic identification of cargo and the status of cargo seals on arriving vehicles at the border?

Method: The use of information communication systems enabled by automatic identification systems (incorporating radio-frequency identification technology) is suggested.

Results: Results obtained by the described simulation model indicate that improvements of up to $82 \%$ with regard to transit time are possible using these techniques.

Conclusion: The findings therefore demonstrate how operations at border posts can be improved through the use of appropriate technology and configuration of the operations.

\section{Introduction}

There is a strong connection between the economic growth of a country and the efficiency of its logistics (Laksmanan \& Anderson 2002). This article presents an investigation of cross-border operations with a view of improving their efficiency. Cross-border operations are an integral part of the economic activities of any country as all countries need to import or export goods owing to the increasing globalisation of trade. The Beitbridge border post, which is located between South Africa and Zimbabwe, will be investigated in detail as it is one of the busiest border posts in sub-Saharan Africa. The aim of this investigation is two-fold: (1) to determine the nature and the underlying causes for the observed delays at this border post and (2) to determine how the observed delays would be affected if the border post operations were to be modernised and reconfigured.

To quantify the impact of the various proposed measures on improving the efficiency of a border post, a few possible approaches can be followed. Firstly, through logical reasoning one can estimate the likely impact of individual factors (e.g. the sharing of data) on processing time. This will, however, ignore the interactions between different activities involving the same consignment, as well as between the simultaneous processing of large numbers of different consignments. Most of the difficulties around border post delays result specifically from the somewhat chaotic behaviour that is observed when high levels of congestion are experienced, resulting in one process being delayed by another and one consignment queuing behind others. The cumulative effect of delayed processes becomes intolerable. This approach will therefore not be able to quantify the likely impact of permutations of various scenarios accurately.

A second possible approach is to perform practical experiments of actual delays at border posts by implementing different sets of operational practices and supporting systems. Although this may yield the most reliable results, the costs and involvement required from independent stakeholders renders it not practically feasible. To some extent this approach was used by Fitzmaurice (2009, 2012) in studies at various border posts, including Chirundu, a border post between Zimbabwe and Zambia. The results from the Chirundu One Stop Border Post (OSBP) study describe the 
impact of a specific set of measures against which the current study can be compared. However, the Chirundu OSBP systems do not include any of the measures investigated in this article.

We opted to construct an accurate model of the current border post and the proposed improved system, and to simulate the expected performance of different scenarios as defined by the different modes of operating the cross-border systems. This allowed the investigation of several different options at a lower cost than with physical deployments. It also allowed for comparing the expected levels of performance for the different scenarios. Based on the results, recommendations could be made for future border systems.

We first present the problem statement for this study, followed by a literature review that informs the analysis of an empirical study performed at a typical border post to measure the average delays experienced by freight (Curtis 2009; Fitzmaurice 2009, 2012). A description of a simulation model for the present border post operations follows, together with validation of the model. Here we discuss the impact of possible alternative configurations for the border post operations based on scenario analysis using the simulation model. The impact of each of the following scenarios was investigated:

- the pre-declaring of consignments

- changing customs processing capacity in response to expected congestion

- information exchange between consignors and customs enabled by auto-identification systems

- the use of a more intelligent customs risk engine and management system (CREMS).

The results of the simulation study are subsequently presented and discussed, followed by concluding remarks. Suggestions for future work are included in the conclusion.

\section{Problem statement}

The need for improving border posts and trade corridors' operational efficiencies has been debated for a long time (Barka 2012; Norov \& Akbarov 2009). In the case of crossborder clearance processes, cargo owners, freight forwarders and cargo transporters are interested in shorter delays in crossing the border posts. However, many governments, particularly in Africa, want to maximise the revenue from customs duties. These governments therefore implement stringent measures at the borders to achieve their objective, which causes long delays at the border posts.

Effective management of road transport is further complicated by a wide spectrum of independent stakeholders being involved. The cross-border movement of a freight consignment involves at least the cargo owner (or consignor), the transporter, sometimes a transport broker, a freight forwarder, a clearing agent, roads agencies, customs authorities on each side of the border, and a customer (or consignee). Commercial players have objectives that are well aligned
TABLE 1: Monitored transit delays at Chirundu border post for north-bound traffic before and after the border post being converted to a one-stop system.

\begin{tabular}{lcc}
\hline Comparative category & $\begin{array}{c}\text { Delay time (hours) in } \\
\text { current system (OSBP) }\end{array}$ & $\begin{array}{c}\text { Delay time (hours) in } \\
\text { previous system (pre-OSBP) }\end{array}$ \\
\hline Clearing agent & 12.31 & 6.00 \\
Customs & 45.27 & 21.00 \\
Driver idle time & 14.06 & 11.00 \\
Immigration & 0.31 & $<1 \mathrm{~min}$ \\
Document processing & 57.58 & 27.00 \\
Inspection time & 1.14 & 1.00 \\
\hline
\end{tabular}

Source: Fitzmaurice, M., 2012, 'TLC report on Beitbridge, Chirundu, Kasumbalesa and Nakonde', report, Transport and Logistics Consultants (TLC), Port Elizabeth OSBP, One Stop Border Post.

and aimed at improved operational efficiencies. Agencies responsible for protecting roads infrastructure and collecting customs duties are, however, more concerned about the effectiveness of control measures aimed at the prevention of illegal practices (Siror et al. 2010) and collection of maximum duties.

Current cross-border freight management systems are characterised by a lack of transparency from the perspective of the consignor and consignee and by little coordination between the actions of different role players. The lack of visibility of operations at ground level typically results in long delays at border posts accompanied by many corrupt practices, which often go hand in hand (Fitzmaurice 2009; Thomas, Khadr \& Girishankar n.d.). Although the lack of integration between the systems operated by different stakeholders is partly to blame, deliberate manipulation of the process by human operators (who know that their actions are difficult to police) also plays a notable role, as shown by empirical data from a comparative study at the Chirundu border post (Fitzmaurice 2012; Mpata 2011) between Zimbabwe and Zambia (Table 1). In an effort to improve the operational efficiency of the Chirundu border post, it was converted from a legacy border post (two different and separately housed customs or immigration authorities) to an OSBP (both authorities housed in one building). Observations from Table 1 indicate that some of the delay times have instead doubled after the conversion, eroding the objectives of an OSBP.

At present, the average transit time for goods to cross the Beitbridge border is 26.88 hours (Fitzmaurice 2012). This average transit time is too high if the exporters or importers are to be competitive at the global level. The aim of this study, therefore, is to investigate the possibility of an improved system that can cater for the needs of all stakeholders. Governments in Africa should be able to enforce regulations effectively as well as maximising collection of revenue in the form of duties. On the other hand, exporters, importers and transporters should enjoy shorter transit times at the border posts. Different measures aimed at improvements are proposed and the impact of each of these, as well as their combined effect, is determined using a simulated model.

\section{Literature review}

Fitzmaurice $(2009,2012)$ conducted fieldwork at designated border posts to determine the causes for long delays. The 
work formed part of the activities of Trade Mark South Africa, which was a trade facilitation initiative funded by the UK government through its Department for International Development. The results of this fieldwork have been used extensively in this article to calibrate the simulation model. As there is limited relevant literature for the work discussed in this article, the work of Fitzmaurice $(2009,2012)$ was useful in many respects. For example, the results of the Chirundu border post study (Table 1) shows that human conduct can have adverse effects on the operation of various systems. The transaction time was expected to be shorter for an OSBP than for a legacy border post. In contrast, the results show the opposite to be true. This was attributed to negative human conduct: customs officials who receive information about approaching consignments earlier have more time to select consignments to be subjected to extortion, leading to increased rather than reduced delay times for such consignments. This observation further supports the view that automating most of the operations and close monitoring of human conduct to foster accountability offer a solution.

In a similar study (Hsu, Shih \& Wang 2009), the processing of import cargo at an air cargo terminal was investigated. A flow network model that includes cargo, information and human flow was developed and the performance was tested. A system based on radio-frequency identification (RFID) was introduced in some operational units to replace some manual operations, such as the cargo identification function and locating the position of cargo. The results showed a decrease in cargo owners' inventory costs and terminal operators' labour costs by about 63\%. Following from the approach proposed by Hsu et al. (2009), Hoffman, Lusanga and Bhero (2013) proposed and developed a related approach for border cargo clearance in the case of non-air cargo. The model reported on in this article essentially builds on that approach through the formulation, design and building of a simulation model.

\section{Fieldwork at the Beitbridge border post}

In this section, the empirical work conducted to evaluate cargo processing time at the Beitbridge border post will be considered. The result of this analysis formed the basis for developing a cargo processing model for border post operations.

\section{Typical flow diagram for border post processes}

Figure 1 shows the process flow diagram for a consignment crossing a typical border post (Fitzmaurice 2012). The activities in the flow diagram in Figure 1 are defined in Table 2. It should be noted that the steps in Figure 1 are for only one side of a border; these steps are repeated on the other side of a border. Also worth noting is that some operations are performed

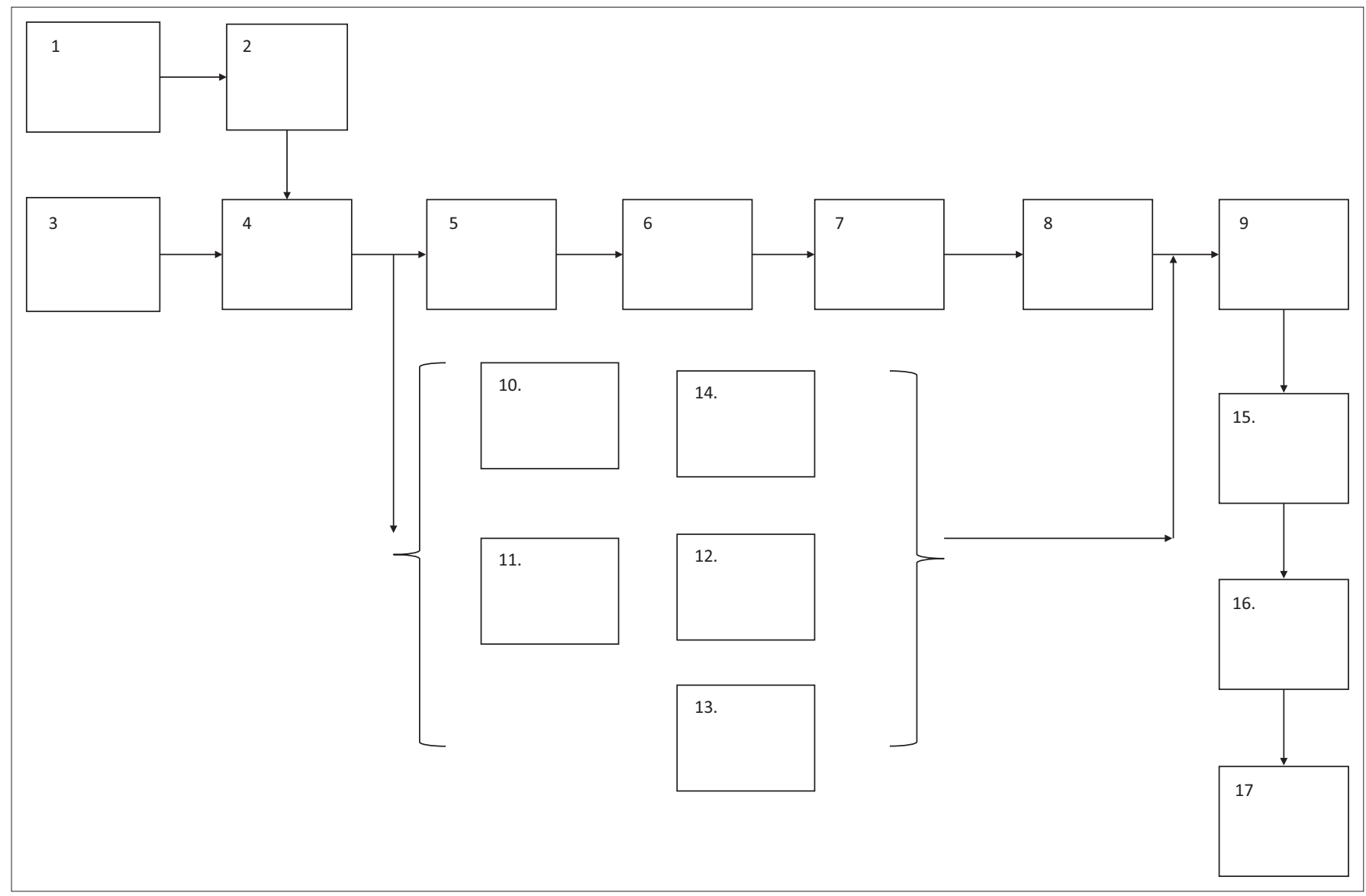

Source: Bhero, E. \& Hoffman, A., 2014, 'Optimizing border-post cargo clearance with auto-ID systems', Journal of Machine to Machine Communication 1, 17-30

FIGURE 1: Typical work flow at a border post, such as Beitbridge between South Africa and Zimbabwe. 
in parallel. For example, when customs officials collect declarations documents for processing (Figure 1, block 8), processes such as the driver going through immigration, vehicle weighing and vehicle scanning can go ahead.

\section{Beitbridge border post cargo transit times}

The cargo transit times presented in this section were obtained from the fieldwork of Fitzmaurice $(2009,2012)$. These results were comparable with those from other sources (Curtis 2009; Globaltrack 2015).

Table 3 shows a breakdown of the processing steps and associated times for consolidated cargo type at the Beitbridge border post. Consolidated cargo was chosen because its processing steps and associated waiting times result in consistently long delays compared with other cargo types. This is because multiple, separate consignors and consignees use a single transporter in a consolidated cargo consignment.

Thus, each cargo owner will have to complete separate declaration forms and each is likely to use a different clearing agent. This explains the long delays reflected in Table 3 and, more importantly, the long delay in waiting for payment of

TABLE 2: Processing steps at a border post.

\begin{tabular}{ll}
\hline Step & Description of activity \\
\hline 1 & Lodging manifest for pre-clearance \\
2 & Pre-clearance and pre-payment \\
3 & Travel from origin to the border \\
4 & Cargo arrives at the border \\
\hline 5 & Driver submits documents to the clearing agent \\
7 & Agent works on the documents before submitting to customs \\
8 & Agent submits documents to customs \\
9 & Customs process clearance \\
10 & Payment of customs duties and other payments \\
11 & Driver goes through immigration \\
12 & Vehicle weighing \\
13 & Physical inspection of cargo \\
14 & Inspections by other border agencies \\
15 & Customs release cargo documents to the agent \\
16 & Agent hands documents to driver \\
17 & Cargo leaves the border \\
\hline Source: Bhero, E. \& Hoffman, A., 2014, 'Optimizing border-post cargo clearance with auto-ID
\end{tabular}
systems', Journal of Machine to Machine Communication 1, 17-30

TABLE 3: Transit times for various processing steps applicable to consolidated cargo at the Beitbridge border post.

\begin{tabular}{lc}
\hline Transaction type & Average transit time (hours) \\
\hline South African clearing agent & 3.7 \\
Zimbabwean clearing agent & 2.7 \\
South African revenue services & 26.2 \\
Zimbabwe revenue authority & 28.5 \\
Driver idle time & 1.8 \\
Weighbridge & 0.6 \\
Waiting for duties & 25.8 \\
Documentation errors & 0.9 \\
Transporter delays & 1.8 \\
Total border transit time & 60.9 \\
\hline Source: Fitzmaurice, M., 2012, 'TLC report on Beitbridge, Chirundu, Kasumbalesa and \\
Nakonde', report, Transport and Logistics Consultants (TLC), Port Elizabeth
\end{tabular}

duties. The total average border transit time (60.9 hours) was calculated as the total delay time (for the steps in Table 3) over 4 months (1950.25 hours) divided by 32 observed cargo trucks (Fitzmaurice 2009)

Table 4 shows the average transit times measured for the four main cargo types that were observed by Fitzmaurice $(2009,2012)$. These transit times represent the time to cross the border. The notable difference in transit time between consolidated cargo and refrigerated cargo relates to refrigerated cargo often consisting of a single commodity or only a few different commodities (usually) from the same exporter, whereas consolidated cargo often has multiple, separate exporters using a single transporter. The same argument applies to the tanker cargo type. The average transit time across all cargo categories shown in Table 4 is 26.88 hours.

Table 5 shows average transit times at a number of regional border posts (South Africa-Zimbabwe, Zimbabwe-Zambia and Zambia-Democratic Republic of Congo) for four consecutive weeks in 3 months in 2015 (Globaltrack 2015). The times are based on satellite, GPS and GSM tracking data.

The average transit time for all cargo types at Beitbridge (South African and Zimbabwean sides combined) has been calculated as 23.75 hours, which is comparable to that reported by Fitzmaurice $(2009,2012)$. In this article, the findings of Fitzmaurice $(2009,2012)$ are used extensively because they present detailed data and analysis not only of the delays associated with each cargo type but also of the delays at every step in the cross-border processing. However, the average transit time calculated from the data in Table 5 conceals underlying disparities (e.g. a delay of up to 60 hours for consolidated cargo). It would be prudent to investigate the economic impact of such delays on operators whose primary means of transport is the consolidated cargo arrangement.

TABLE 4: Average transit times for different cargo types based on data measured at Beitbridge border post.

\begin{tabular}{lc}
\hline Cargo type & Average transit time (hours) \\
\hline Consolidated & 60.9 \\
Refrigerated & 7.5 \\
Break bulk & 30.2 \\
Tanker & 8.9 \\
\hline Across all cargo types & $\mathbf{2 6 . 9}$ \\
\hline Source: Fitzmaurice, M., 2012, 'TLC report on Beitbridge, & Chirundu, Kasumbalesa and
\end{tabular}

Source: Fitzmaurice, M., 2012, 'TLC report on Beitbridge, Chirundu, Kasumbalesa and Nakonde', report, Transport and Logistics Consultants (TLC), Port Elizabeth

TABLE 5: Average transit times at a number of regional border posts, based on satellite, global positioning system or mobile system tracking.

\begin{tabular}{lccccc}
\hline Border post $\uparrow$ & Week 1 & Week 2 & Week 3 & Week 4 & $\begin{array}{c}\text { Average over } \\
\text { period }\end{array}$ \\
\hline Beitbridge (South Africa) & 17 & 15 & 14 & 14 & 15 \\
Beitbridge (Zimbabwe) & 8 & 9 & 8 & 10 & 9 \\
$\begin{array}{l}\text { Chirundu (Zambia) } \\
\text { Chirundu (Zimbabwe) }\end{array}$ & 15 & 14 & 14 & 22 & 16 \\
$\begin{array}{l}\text { Kasumbalesa (Democratic } \\
\text { Republic of Congo) }\end{array}$ & 26 & 29 & 28 & 26 & 27 \\
$\begin{array}{l}\text { Kasumbalesa (Zambia) } \\
\text { Source Tranit tim }\end{array}$ & 70 & 18 & 17 & 26 & 32 \\
\hline
\end{tabular}

Source: Transit times supplied by Globaltrack (http://www.globaltrack.com) $\dagger$, Country designations refer to the side of the border. 


\section{Simulation of processes at a border post}

In this section, a simulation model for typical border post processes is discussed, based largely on what Hoffman et al. (2013) proposed. The simulation results for the legacy system (i.e. the status quo of operations and systems) are first compared to the empirical data, with the model then being refined until the simulated results concur with reality. This serves to validate the model, increasing the level of confidence in the results generated for modified scenarios. Once the simulated model is calibrated in this way, the proposed new concepts can be added and the associated changes in behaviour can be studied.

The simulation model was implemented using Simio simulation software (Simio 2013). Simio supports objectoriented simulation and facilitates rapid development and simulation of complex systems (Kelton, Smith \& Sturrock 2014). In developing the simulation model, the steps causing the longest delays (Table 3) were incorporated. In a queuing system, the step associated with the longest delay is a determining factor of the time spent in the queuing system. Thus, a detailed state flow diagram was constructed for each participating entity and for each of the essential steps in the process (see Figure 2). This allows the model to measure time spent within each process step and the impact of each input factor on these process times, exposing the internal variability for various system steps and their sensitivity to various factors. In the process it was possible to develop a realistic simulation model that can be used to refine the various design parameters of an overall cross-border system.

\section{Flow diagram of operations at a typical border post}

Figure 2 shows a portion of the flow diagram for operations at a border post:

- Block 1 represents the number of clearing agents stationed at the border. In the simulation model, eight clearing agents were assumed; in reality, the number of agents at the border far exceeds eight. A Poisson distribution is used for the processing time associated with a clearing agent (Kelton et al. 2014). A Poisson distribution was preferred over a Gaussian distribution as it ensured that processing time would always be positive whilst allowing for a gradual reduction in probability as processing time increases beyond the average time.

- Block 2 represents a number of customs teams. In the simulation model, the number of working teams was variable. A triangular distribution model is applied owing to the large variability in processing time due to the type of cargo; even for the same cargo type, there is substantial variability in processing time. The triangular distribution caters for the minimum, mean and maximum observed transit times.

- Block 3 represents possible delays that can occur due to error in documentation. A Poisson distribution is used.

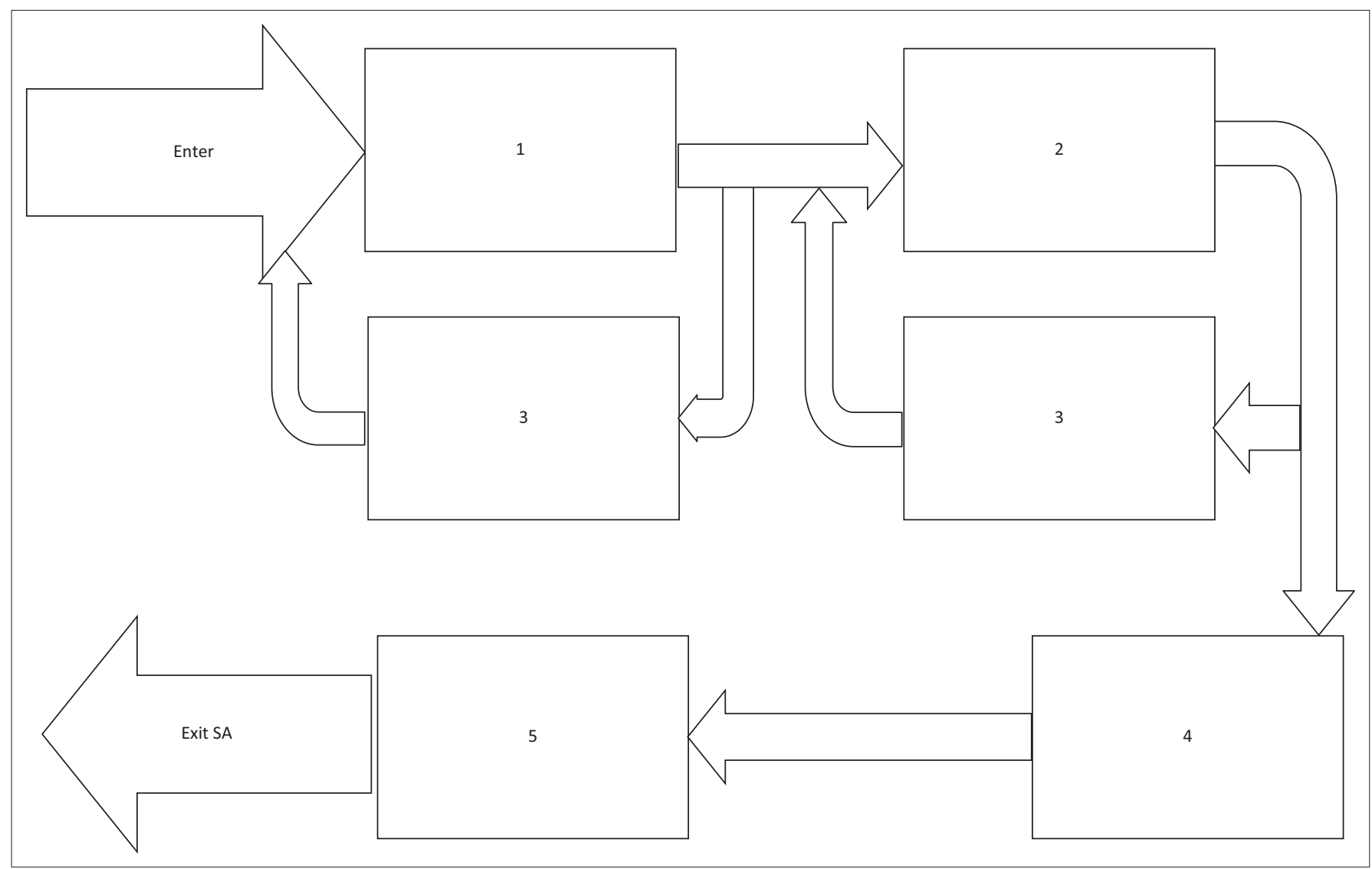

FIGURE 2: Flow diagram of typical processes at a border post. 
- In block 4 a triangular distribution is used owing to the large variability in processing time based on cargo type.

- Block 5 includes steps such as immigration, weighing and scanning processes. These operations represent minimal delay times at the border posts and a Poisson distribution is used for each.

Owing to restricted space, Figure 2 represents a condensed version of the actual flow diagram that was fed into the simulation software. It is worth noting that the steps shown in Figure 2 are repeated when cargo enters the destination country at the next border.

Figure 3 shows a detailed logic flow diagram for border post operations.

This flow diagram indicates possible sources of long delays in the present operations at border posts:

- Block 1: Both Fitzmaurice $(2009,2012)$ and Curtis (2009) reported that drivers often do not submit clearing documents to the clearing agent immediately when they arrive at the border. Drivers are likely to first engage in personal activities before handing over documents to the clearing agent. The reports indicate that these delays can last up to 4.5 hours. Therefore, this part of border processes needs to be improved if border transit time is to improve.

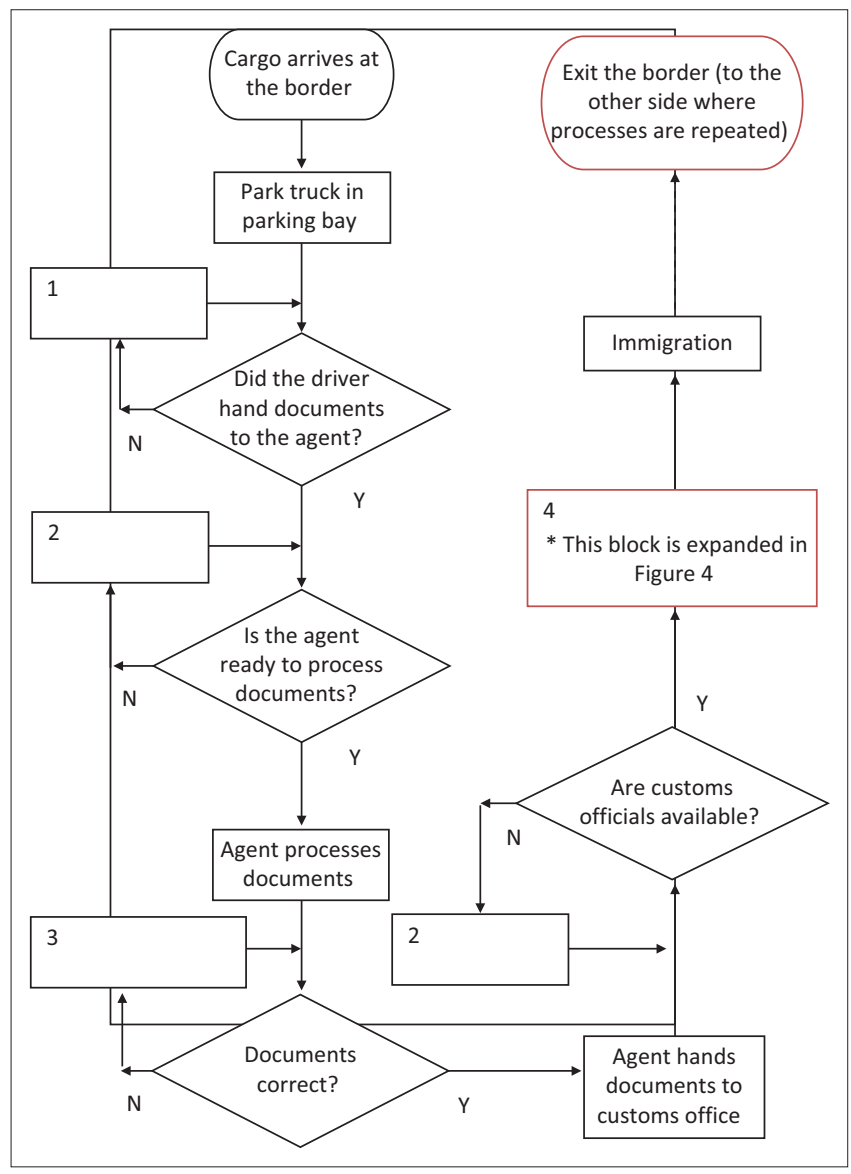

$\mathrm{N}, \mathrm{no}$; Y yes

FIGURE 3: Logic flow diagram for typical operations at a border post.
- Block 2: Adding declaration documents to a queue is understandable because the number of clearing agents at the border is finite and a minimum of 1.1 hours is required to process documents (Fitzmaurice 2009, 2012). The same argument applies to the customs officials when there is no available (i.e. unoccupied) customs official to start processing an incoming declaration (block 2). Queuing documents causes the average processing time at these steps to increase unduly. It can therefore be stated that these parts of border processes need to be improved if transit time is to improve.

- Block 3: The delays due to errors in the documents are minimal compared with delays associated with other processes such as customs (Fitzmaurice 2009, 2012). For example, consolidated cargo was reported to have an average delay of approximately 1 hour whereas refrigerated cargo had no delay time. As consolidated cargo often consists of cargo from several separate importers or exporters, multiple declarations are often tendered, which increases the probability of errors.

- Block 4 represents the most significant component of delays in border transit time. For this reason, the internal processes within this block are expanded and illustrated in Figure 4.

The flow diagram in Figure 3 offers a suitably accurate process model for operations at a border post. However, there are other minor delays that are not apparent from Figure 3. These include queuing of trucks to go through the border gates, queuing to enter the inspection bay, queuing to enter the scanning bay, and so on.

Figure 4 shows a detailed state diagram for customs processes. A state diagram shows the behaviour of a system that is triggered by a specific event. The customs officials manually inspect the declaration documents for errors and infractions, physically inspect the majority of cargo and then capture declarations (for duty determination) on a computer.

It is evident from Figures 3 and 4 that in most of the steps associated with delays, notable human action is required. What is being proposed, therefore, is the reduction of human involvement in operations at a border post and, at a bigger scale, in all multinational trade corridors. Extensive use of auto-identification systems is proposed, including GPS tracking of consignments from origin to border post, barcodes to scan documents, and RFID technology to identify vehicles arriving at processing points and to check cargo seals. In this article only a subset of the proposed auto-identification techniques is investigated; the rest will be addressed in future research.

From Figure 1 and Table 3 it is apparent that customs processes (document processing performed by customs officials and the clearing agents) contribute the longest delays. Currently customs authorities such as the South African Revenue Services already use electronic data interchange between the cargo owners or their agents and the customs 
authorities. The manual verification of documents carried by the driver at the border is, however, still compulsory. This not only results in delays and mistakes, but also offers a convenient opportunity for drivers who wish to extend their stay at the border.

Thus, it is proposed that electronic documents (with essential information encoded as 2D barcodes or embedded with an RFID tag) are used to carry the most important information as normally found in the manifest document and declaration or consignment data. Scanning of documents will not only eliminate many human errors, but also provide an electronically captured record of when documents changed hands. This will allow the consignor and consignee to obtain valuable insight into the status of operations at the border

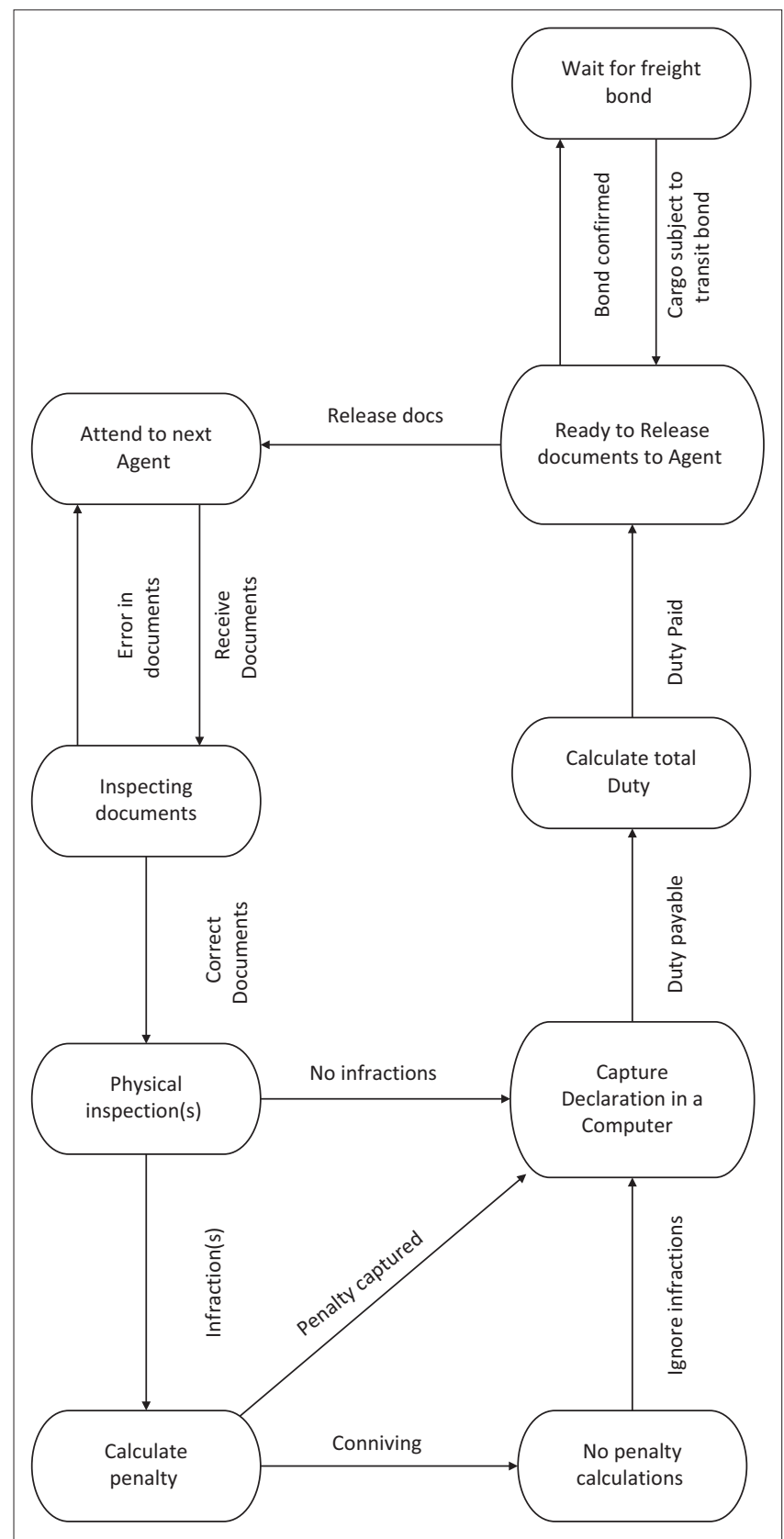

FIGURE 4: State diagram of internal processes during customs processing at a border post (expanded from Figure 3 ). and allow delays and processing times to be recorded and measured.

In addition, it is proposed that cargo vehicles are tagged so that the RFID readers at the entrance to the border can automatically identify consignments as they arrive. The consignment identity can then be fed to the control centre, which initiates immediate processing of the consignment. The CREMS of the customs authority will determine the risk profile of the consignment and alert the inspection team(s) whether to physically inspect a particular cargo or not. This will furthermore enable compliant consignments to be separated from potentially non-compliant consignments upon arrival at the border, preventing a situation where fully compliant consignments have to queue behind noncompliant ones. This process of physically separating consignments upstream from where the clearing process takes place is depicted in Figure 5 (Hoffman et al. 2013).

All the mentioned information interchange is achieved electronically, which improves the rate of document and vehicle processing. The human labour freed from these tasks can thus be deployed elsewhere, typically to inspect suspicious consignments detected earlier. Implementing the described system can substantially reduce human involvement in the processing of consignments and can eliminate face-to-face contact between customs officials and transporters for fully compliant consignments. This can eliminate the primary cause of corruption and unnecessary delays. The proposed system is therefore expected to improve the performance at border posts with regard to not only speed but also accuracy and transparency (Bhero \& Hoffman 2014).

\section{Simulation model for typical border post processes}

Based on the process flow diagrams representing the current system (Figures 2,3 and 4), a simulation model was developed using the Simio simulation package. The simulation model was calibrated using historical field data on transit times

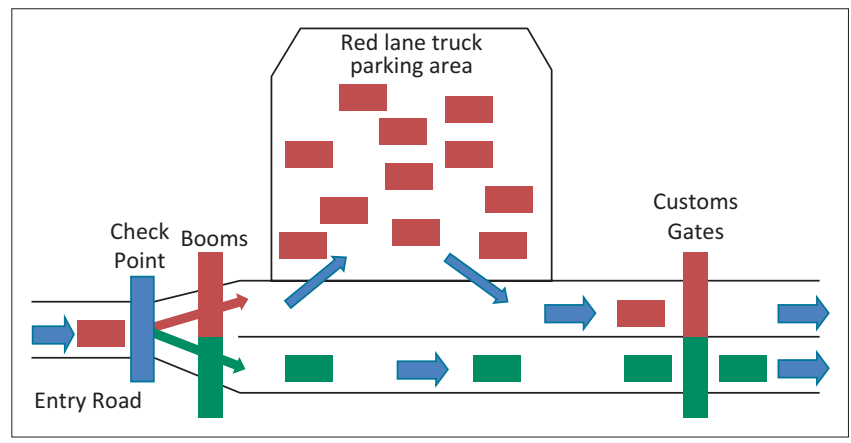

Source: Bhero, E. \& Hoffman, A., 2014, 'Optimizing border-post cargo clearance with auto-ID systems', Journal of Machine to Machine Communication 1, 17-30 and Hoffman, A., Lusanga, K. \& Bhero, E., 2013, A combined GPS/RFID system for improved cross-border management of freight consignments, in Proceedings of AFRICON 2013, Pointe-aux-piments, Mauritius, September 9-12, 2013

FIGURE 5: Schematic layout at a border post to facilitate separating consignments upstream from the clearing process. Compliant cargo is processed along the green lane, whereas non-compliant cargo is processed along the red lane. 
TABLE 6: Comparison of simulated and measured transit times for processing of various cargo types at the Beitbridge border post.

\begin{tabular}{lccc}
\hline Cargo type/Process stage & \multicolumn{2}{c}{ Time in system } & $\begin{array}{c}\text { Standard } \\
\text { deviation }\end{array}$ \\
\cline { 2 - 3 } & $\begin{array}{c}\text { Field data } \\
\text { (hours) }\end{array}$ & $\begin{array}{c}\text { Simulation } \\
\text { (hours) }\end{array}$ & \\
\hline South African side: Customs & 11.95 & 10.69 & 3.44 \\
\hline Zimbabwean side: Customs & 15.05 & 9.66 & 2.81 \\
South African side: Break bulk & 8.40 & 11.08 & 3.28 \\
Zimbabwean side: Break bulk & 12.80 & 10.22 & 2.72 \\
Break bulk & 30.20 & 27.01 & 5.11 \\
Consolidated & 60.90 & 51.25 & 5.18 \\
Refrigerated & 7.50 & 15.17 & 5.51 \\
Tankers & 8.90 & 14.82 & 5.34 \\
\hline All cargo & $\mathbf{2 6 . 8 8}$ & $\mathbf{2 6 . 3 7}$ & $\mathbf{5 . 5 0}$ \\
\hline
\end{tabular}

for various cargo types. For each scenario investigated, the simulator was run for a period of 500 hours, with each run comprising 200 replications. The results of the simulation are shown in Table 6.

The simulation results in Table 6 are within an acceptable range compared with the field data. Considering simulation results and the corresponding standard deviations $(\sigma)$, we note that five of the simulation results are within a $1 \sigma$ range and three of the results are within a $2 \sigma$ range. Confidence intervals of $90 \%, 95 \%$ and $99 \%$ are common for studies of this nature (Wegner 2012). Furthermore, it is unrealistic to expect very high precision levels, given the inherent uncertainties related to human actions.

The simulated times for tanker and the refrigerated cargo are higher than those observed in field data. As the simulated system is essentially a queuing problem, the delay of other cargo still impacts on the average delay of all other cargo. The transit times associated with tanker and refrigerated cargo are the shortest and are likely to be affected the most.

The average delay simulated across all cargo types is 26.37 hours compared to 26.88 hours for field data (Table 4) and 23.75 hours for tracking data (Table 5). All simulated times are within the $1 \sigma$ range. It can, therefore, be concluded that the simulator has been calibrated within an acceptable range of statistical uncertainty (Wegner 2012).

After calibrating the model, experiments were set up to test the following scenarios.

\section{Pre-declaring facility (scenario 1)}

In this scenario, the objective was to determine the potential effect of pre-declaring cargo on the border transit time. In pre-declarations, the declaration documentation is sent to the clearing agent before the cargo leaves the depot of origin. The rationale is that the clearing agent will process the documents, hand them over to customs for processing and possibly pay any required duties before the cargo arrives at the border. Therefore, by the time the cargo arrives, less time is expected to be spent at the border. However, although cargo would have been pre-declared, it is possible that it could still be subjected to intrusive inspection by customs officials depending on the cargo or exporter risk profile or any other reasons that the customs officials may see fit.

In running this scenario, the percentage of cargo that is predeclared was varied from $0 \%$ to $100 \%$. Customs capacity was set at six on either side of the border. The border transit time was expected to decrease as the delays associated with the steps in block(s) 2 and block 3 in Figure 3 were expected to be eliminated or substantially reduced. In Figure 4, delays associated with inspecting documentation and physical inspections are expected to be similarly mitigated. It should be mentioned that in the simulation only the input percentage of pre-declared cargo is deterministic and all other processes are stochastic.

\section{Processing capacity at customs (scenario 2)}

Here the objective was to determine the impact of the processing capacity at customs on the border transit time. As customs processing contributes the longest delay in cargo processing, the rationale for this scenario was to determine the impact of parallel processing by customs on border transit time.

The processing capacity was varied from a minimum of six officials to a maximum of 25 officials working on processing and clearing cargo on either side of the border. The procedure for varying capacity involved increasing the number of customs officials by one in a sequential way on both sides of the border post and then recording the impact on processing time.

\section{Combined strategies (scenario 3)}

In this scenario, the objective was to determine the combined impact of pre-declaring cargo and customs processing capacity on the border transit time - a combination of scenarios 1 and 2. The proportion of cargo that is predeclared was gradually increased whilst the processing capacity was kept constant. This procedure was repeated several times, with the processing capacity being changed for each new repeat. Border transit times were observed and compared.

\section{An radio-frequency identification-enabled system (scenario 4)}

Here the objective was to determine the impact of using the proposed RFID-enabled system on the border transit time. A combination of electronic pre-declaration, use of autoidentification systems (based on RFID technology) and the intelligent and dynamic changing of processing capacity at customs were investigated. In the proposed system, the term 'compliant cargo' is preferred to 'pre-declared cargo'. Compliant cargo can loosely be defined as cargo for which the importer or exporter has made information available upfront to allow automated verification by means of appropriate technologies and is administrated by an importer or exporter who has a track record of good business ethics and integrity. 
For intelligent, dynamically changing customs processing, it is proposed that customs authorities will be running a more intelligent risk engine. CREMS can, amongst others:

- communicate with the exporter or importer systems to facilitate electronic pre-declarations; information about when cargo leaves the depot of origin is used for estimating arrival time and hence volumes at the border at certain times

- communicate electronically with road agents, for example the South African National Roads Agency, to get information on cargo deviations on the way to the border

- advise the supervisory customs authority on expected arrival volumes at certain periods to allow anticipative increase in processing capacity

- keep a record of individual customs officials' efficiency profile or the type of cargo or specific exporter or importer often attended to by the official, which could expose potential malpractices.

The majority of these attributes of CREMS will be considered in future work; however, some preliminary features of CREMS were implemented in the current study. In this article, the research focuses on the impact of information interchange between exporters or importers and the customs

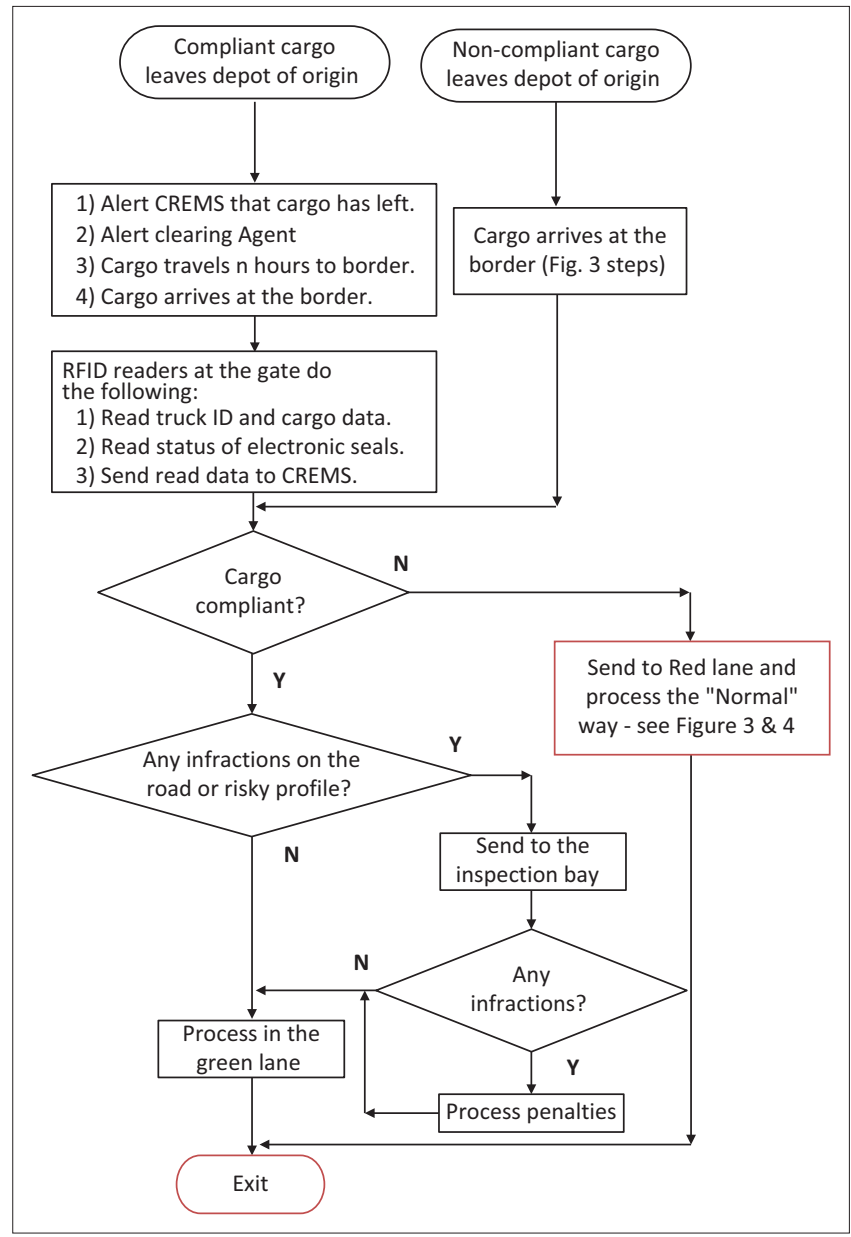

$N$, no; Y, yes.

FIGURE 6: Condensed process flow diagram with proposed implementation of an RFID-enabled system at a border post. system. Therefore the proportion of compliant cargo was gradually increased from $0 \%$ to $100 \%$ whilst the simulation model was set to change processing capacity at the border adaptively in response to alerts from cargo as it left the depot of origin. The message packet includes the town of origin and departure time, which enables CREMS to estimate travelling time and hence possible arrival volumes. The border transit times were then observed.

Figure 6 shows a condensed process flow diagram at the border for the proposed RFID-enabled system. The essential features of the system include:

- substantial information exchange amongst stakeholders

- automation of many of the cross-border trade operations

- faster processing of compliant cargo as many humandependent stages will be automated

- monitoring and policing of infractions throughout the cross-border trade corridor, with officials being held accountable.

\section{Simulation results}

The results of the scenarios discussed in the previous section are presented here.

\section{The impact of pre-declaring (scenario 1)}

The proportion of cargo that is pre-declared was gradually increased and border transit times determined. The results are summarised in Table 7 , with the resultant graph shown in Figure 7.

The results show that the average transit time across all cargo types decreased from 26.41 hours to a minimum of 12.53 hours at $70 \%$ of pre-declared cargo and then increased slightly to 13.60 hours at $100 \%$ pre-declared cargo. A continuous decrease is observed only for consolidated cargo; transit times for all other cargo types decrease to a minimum and then increase again slightly. This is because the number of customs officials was fixed in the simulation. Thus, as more cargo is pre-declared the demand to process pre-declarations increases beyond the processing capacity. Consignments that are normally processed very quickly (refrigerated and

TABLE 7: Simulated total transit times for different types of cargo at Beitbridge border post when pre-declaring was implemented.

\begin{tabular}{lccccc}
\hline $\begin{array}{l}\text { Percentage } \\
\text { pre-declaration }\end{array}$ & $\begin{array}{c}\text { All cargo } \\
\text { (hours) }\end{array}$ & $\begin{array}{c}\text { Break bulk } \\
\text { cargo } \\
\text { (hours) }\end{array}$ & $\begin{array}{c}\text { Consolidated } \\
\text { cargo } \\
\text { (hours) }\end{array}$ & $\begin{array}{c}\text { Refrigerated } \\
\text { cargo } \\
\text { (hours) }\end{array}$ & $\begin{array}{c}\text { Tanker } \\
\text { cargo } \\
\text { (hours) }\end{array}$ \\
\hline 0 & 26.41 & 27.01 & 51.29 & 15.16 & 14.85 \\
10 & 20.87 & 21.36 & 43.68 & 10.46 & 10.14 \\
\hline 20 & 17.52 & 18.04 & 37.68 & 8.47 & 8.03 \\
\hline 30 & 15.63 & 16.03 & 33.78 & 7.59 & 7.17 \\
40 & 14.44 & 14.64 & 30.15 & 7.42 & 6.96 \\
\hline 50 & 13.51 & 13.68 & 26.88 & 7.69 & 7.11 \\
60 & 12.89 & 13.00 & 24.05 & 8.18 & 7.61 \\
\hline 70 & 12.53 & 12.52 & 21.38 & 8.87 & 8.34 \\
\hline 80 & 12.54 & 12.37 & 19.41 & 9.95 & 9.37 \\
\hline 90 & 12.76 & 12.48 & 17.57 & 11.21 & 10.64 \\
100 & 13.60 & 13.20 & 16.32 & 13.04 & 12.52 \\
\hline
\end{tabular}


tankers) now have to compete with pre-declared consolidated consignments for the available customs processing capacity. Consolidated cargo shows continuous decrease because it was originally associated with a very high transit time compared with other cargo types.

\section{The impact of processing capacity at customs (scenario 2)}

The processing capacity at customs was varied from a minimum of six officials to a maximum of 25 officials on either side of the border. The resulting border transit times are summarised in Table 8, with the resultant graph shown in Figure 8.

The results show that as the processing capacity at customs increases (more customs officials available), cargo transit time decreases. This is in line with the expected outcome. A notable observation from these results is that the transit time across all cargo types levels off close to 17 hours, which is associated with a processing capacity of about 20 (10 officials on each side of the border). Beyond this capacity, the decrease in transit time becomes almost neglible. For example, at a capacity of nine officials on each side (total of 18 across both sides), the transit time is 17.85 hours. At a capacity of

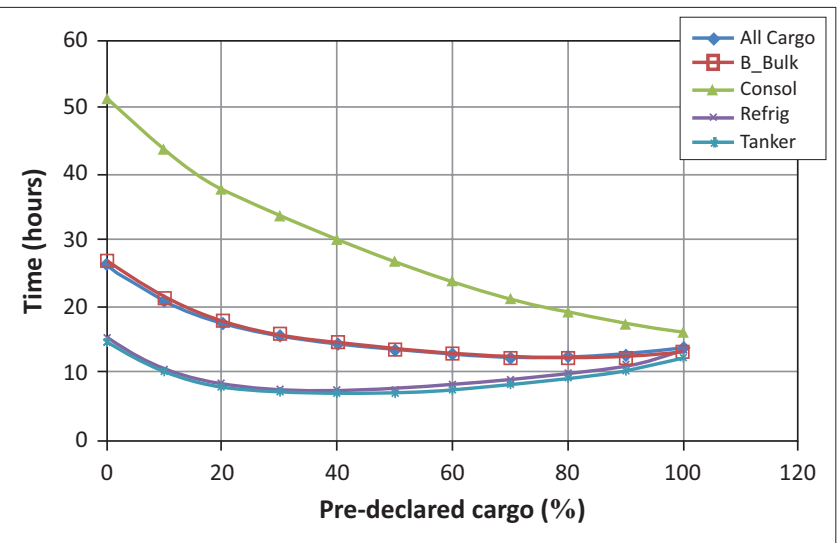

B_Bulk, break bulk cargo; Consol, consolidated cargo; Refrig, refrigerated cargo.

FIGURE 7: Graph showing the effect of pre-declaration on simulated total transit times for different types of cargo at Beitbridge border post.

TABLE 8: Simulated border transit time for different types of cargo at Beitbridge border post for varying levels of processing capacity at customs.

\begin{tabular}{lccccc}
\hline $\begin{array}{l}\text { Processing } \\
\text { capacity } \\
\text { (number of } \\
\text { officials) }\end{array}$ & $\begin{array}{c}\text { All cargo } \\
\text { (hours) }\end{array}$ & $\begin{array}{c}\text { Break bulk } \\
\text { cargo } \\
\text { (hours) }\end{array}$ & $\begin{array}{c}\text { consolidated } \\
\text { cargo } \\
\text { (hours) }\end{array}$ & $\begin{array}{c}\text { Refrigerated } \\
\text { cargo } \\
\text { (hours) }\end{array}$ & $\begin{array}{c}\text { Tanker } \\
\text { cargo } \\
\text { (hours) }\end{array}$ \\
\hline 12 & 26.41 & 27.01 & 51.29 & 15.16 & 14.85 \\
13 & 24.27 & 24.99 & 49.36 & 12.95 & 12.53 \\
14 & 20.49 & 21.13 & 45.71 & 9.01 & 8.68 \\
15 & 19.52 & 20.31 & 44.97 & 8.10 & 7.72 \\
16 & 18.59 & 19.26 & 43.88 & 7.19 & 6.78 \\
17 & 18.14 & 18.81 & 43.55 & 6.75 & 6.34 \\
18 & 17.85 & 18.53 & 43.23 & 6.47 & 6.04 \\
19 & 17.47 & 18.22 & 42.80 & 6.23 & 5.75 \\
\hline 20 & 17.39 & 18.09 & 42.84 & 6.11 & 5.61 \\
30 & 17.12 & 17.83 & 42.49 & 5.80 & 5.33 \\
50 & 17.10 & 17.82 & 42.55 & 5.83 & 5.34 \\
\hline
\end{tabular}

25 officials on each side of the border (a total of 50 across both sides), the transit time is 17.10 hours. This represents a change of 0.75 hours for a 15-official increase in capacity.

The result shows that simultaneous processing by customs officials has a limit beyond which it ceases to be beneficial. It further shows that to achieve better performance in a system that involves a series of potentially parallel processing units, coordination of the various units is required; that is, some form of inter-unit (inter-process) communication is needed. For example, increasing customs capacity may require a corresponding increase in the number of duty payment counters or clearing agents.

\section{The impact of combined strategies (scenario 3)}

The percentage of cargo that is pre-declared was gradually increased whilst the processing capacity was kept constant for each run. Earlier results (Figure 8) showed that a capacity of ten officials on either side of the border is optimal. Therefore, only the results for the case of varying the percentage of predeclarations with ten officials on either side are shown. It

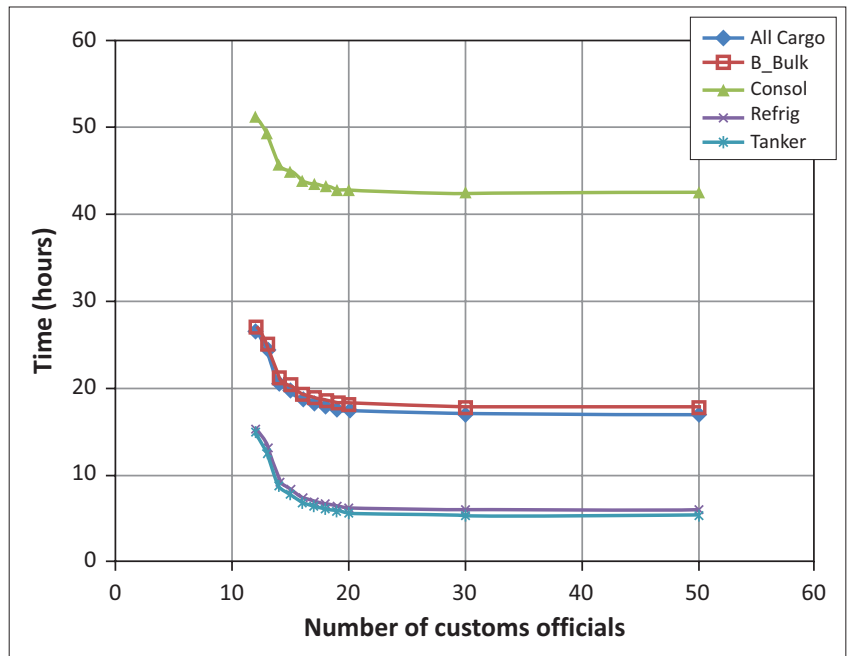

B_Bulk, break bulk cargo; Consol, consolidated cargo; Refrig, refrigerated cargo.

FIGURE 8: Graph showing the effect of varying levels of processing capacity on simulated border transit time for different types of cargo at Beitbridge border post.

TABLE 9: Simulated border transit time for different types of cargo at Beitbridge border post with combined effect of pre-declaration and processing capacity.

\begin{tabular}{lccccc}
\hline $\begin{array}{l}\text { Percentage } \\
\text { pre-declaration }\end{array}$ & $\begin{array}{c}\text { All cargo } \\
\text { (hours) }\end{array}$ & $\begin{array}{c}\text { Break bulk } \\
\text { cargo } \\
\text { (hours) }\end{array}$ & $\begin{array}{c}\text { Consolidated } \\
\text { cargo } \\
\text { (hours) }\end{array}$ & $\begin{array}{c}\text { Refrigerated } \\
\text { cargo } \\
\text { (hours) }\end{array}$ & $\begin{array}{c}\text { Tanker } \\
\text { cargo } \\
\text { (hours) }\end{array}$ \\
\hline 0 & 17.40 & 18.09 & 42.84 & 6.11 & 5.61 \\
\hline 10 & 16.34 & 16.99 & 39.34 & 6.15 & 5.71 \\
\hline 0 & 15.48 & 15.92 & 36.00 & 6.36 & 5.87 \\
30 & 14.61 & 15.00 & 32.63 & 6.61 & 6.15 \\
\hline 40 & 13.91 & 14.19 & 29.70 & 7.05 & 6.50 \\
\hline 50 & 13.29 & 13.48 & 26.58 & 7.58 & 6.95 \\
60 & 12.85 & 12.90 & 24.17 & 8.11 & 7.51 \\
\hline 70 & 12.54 & 12.52 & 21.36 & 8.90 & 8.37 \\
80 & 12.53 & 12.37 & 19.40 & 9.97 & 9.36 \\
90 & 12.77 & 12.48 & 17.57 & 11.20 & 10.64 \\
100 & 13.60 & 13.20 & 16.32 & 13.04 & 12.52 \\
\hline
\end{tabular}

Note: Processing capacity was set at ten on either side of the border. 
should be noted that the starting value for average transit time for all cargo types is set at 17.40 hours, because the starting customs capacity is ten officials (see Table 8). The results for scenario 3 are summarised in Table 9 and the resultant graph is shown in Figure 9.

The average transit time across all cargo types decreased from 17.40 hours to a minimum of 12.53 hours at $80 \%$ of predeclared cargo and then increased slightly to 13.60 hours at $100 \%$ pre-declared cargo. As explained earlier, this is because the number of customs officials was set to a fixed number in this scenario of the simulation. Thus, as more and more cargo is pre-declared, the demand for customs processing capacity increases beyond what is available; hence the increase after reaching a minimum.

\section{The impact of an radio-frequency identification- enabled system without information exchange (scenario 4)}

In scenario 4 , the percentage of compliant cargo (which is therefore processed along the green lane [Figure 5]) was gradually increased and border transit times determined. The results are summarised in Table 10, with the resultant graph shown in Figure 10.

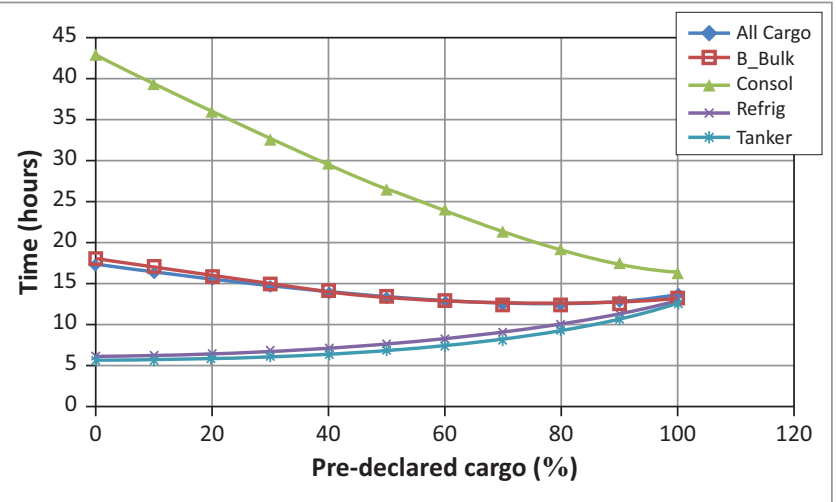

B_Bulk, break bulk cargo; Consol, consolidated cargo; Refrig, refrigerated cargo.

FIGURE 9: Graph showing the combined effect of pre-declaration and processing capacity on simulated border transit time for different types of cargo at Beitbridge border post.

TABLE 10: Simulated border transit time for different cargo types at Beitbridge border post based on a radio-frequency identification-enabled system.

\begin{tabular}{lccccc}
\hline $\begin{array}{l}\text { Percentage } \\
\text { pre-determined } \\
\text { compliance }\end{array}$ & $\begin{array}{c}\text { All cargo } \\
\text { (hours) }\end{array}$ & $\begin{array}{c}\text { Break bulk } \\
\text { cargo } \\
\text { (hours) }\end{array}$ & $\begin{array}{c}\text { Consolidated } \\
\text { cargo } \\
\text { (hours) }\end{array}$ & $\begin{array}{c}\text { Refrigerated } \\
\text { cargo } \\
\text { (hours) }\end{array}$ & $\begin{array}{c}\text { Tanker } \\
\text { cargo } \\
\text { (hours) }\end{array}$ \\
\hline 0 & 26.41 & 27.01 & 51.29 & 15.16 & 14.85 \\
\hline 10 & 20.42 & 21.05 & 42.84 & 10.30 & 9.94 \\
20 & 16.63 & 17.30 & 36.16 & 7.65 & 7.32 \\
30 & 14.15 & 14.63 & 31.22 & 6.31 & 6.03 \\
40 & 12.39 & 12.80 & 27.00 & 5.71 & 5.45 \\
50 & 11.06 & 11.35 & 22.98 & 5.42 & 5.24 \\
60 & 9.86 & 10.09 & 19.37 & 5.43 & 5.26 \\
70 & 8.91 & 9.11 & 15.92 & 5.59 & 5.49 \\
\hline 80 & 8.17 & 8.33 & 12.83 & 5.94 & 5.88 \\
90 & 7.58 & 7.61 & 10.01 & 6.47 & 6.40 \\
100 & 7.17 & 7.16 & 7.16 & 7.18 & 7.19 \\
\hline
\end{tabular}

RFID, radio-frequency identification.
The results show that the average transit time across all cargo types decreased from 26.41 hours to a minimum of 7.17 hours for $100 \%$ compliant cargo. The refrigerated and tanker cargo are the only types that initially decrease and then slightly increase as the percentage of compliant cargo approaches $100 \%$.

In this scenario, the processing capacity associated with the red lane was set at six on either side of the border, whereas the processing capacity associated with the green lane was set at three on either side of the border.

A similar explanation for the results is offered as for scenario 1. As shown in Figure 6, compliant cargo in the proposed system is processed through the 'green lane' (Figure 5). Thus, as the percentage of compliant consignments increases, the processing capacity of the green lanes is adversely affected. Therefore, cargo with shorter processing time is expected to experience additional queuing time. In this experiment, the processing capacity of the green lane was kept constant. As human-dependent processes are eliminated or minimised in the green lane (Figure 6), the RFID-enabled system is expected to process cargo faster. This explains the minimum of 7.17 hours observed for scenario 4 .

\section{The impact of an radio-frequency identification- enabled system with information exchange (extension of scenario 4)}

Here the proportion of compliant cargo was gradually increased and border transit times determined. In addition, exchange of information was enabled. As explained earlier, as cargo leaves the depot of origin it sends a message to the customs system. This information exchange allows CREMS to estimate expected volumes of arrivals and allocate processing capacity accordingly. The results are summarised in Table 11, with a graphical representation shown in Figure 11.

The results show that, compared to the basic conditions of scenario 4, information exchange further improves

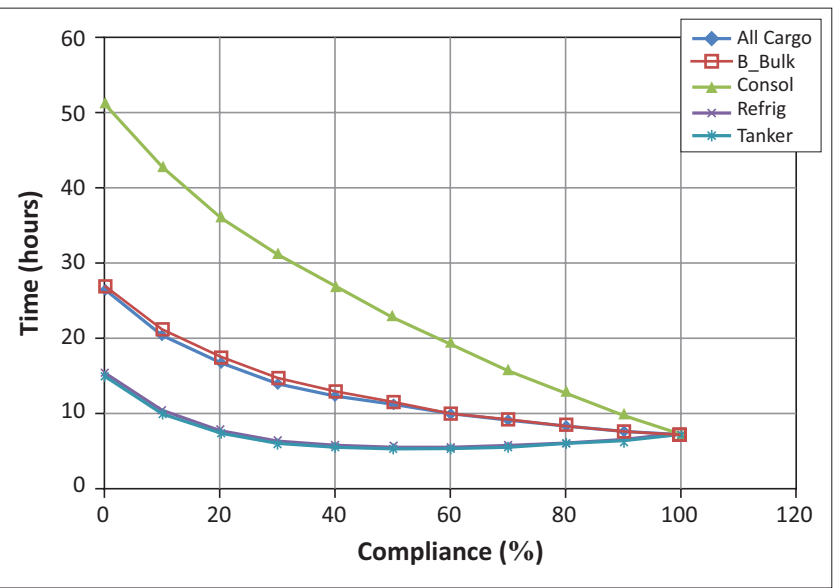

B Bulk, break bulk cargo; Consol, consolidated cargo; Refrig, refrigerated cargo; RFID, radiofrequency identification.

FIGURE 10: Graph showing the effect of implementing an RFID-enabled system on simulated border transit time for different cargo types at Beitbridge border post. In this system, no information exchange was possible. 
performance in an RFID-enabled system. With information exchange, all cargo types experience steady decreases in transit time as the percentage of compliant cargo increases (minimum transit time of 4.83 vs 7.17 hours).

In this experiment, the processing capacity of the red lane was fixed at six on either side of the border, whereas the capacity for the green lane changed dynamically from a minimum of three to a maximum of six on either side of the border.

\section{Comparison of transit time for the various investigated solutions}

Figure 12 compares the simulated transit times found with the various investigated solutions. The figure shows the impact of the following conditions on transit time across all cargo types:

- pre-declaration

- processing capacity at customs

- combined pre-declaration and processing capacity at customs

- an RFID-enabled system without information exchange other than at the border itself

- an RFID-enabled system with information exchange throughout the trade corridor.

TABLE 11: Simulated border transit time for different types of cargo at Beitbridge border post based on a radio-frequency identification-enabled system that allows information exchange.

\begin{tabular}{lccccc}
\hline $\begin{array}{l}\text { Percentage } \\
\text { pre-determined } \\
\text { compliance }\end{array}$ & $\begin{array}{c}\text { All cargo } \\
\text { (hours) }\end{array}$ & $\begin{array}{c}\text { Break bulk } \\
\text { cargo } \\
\text { (hours) }\end{array}$ & $\begin{array}{c}\text { Consolidated } \\
\text { cargo } \\
\text { (hours) }\end{array}$ & $\begin{array}{c}\text { Refrigerated } \\
\text { cargo } \\
\text { (hours) }\end{array}$ & $\begin{array}{c}\text { Tanker } \\
\text { cargo } \\
\text { (hours) }\end{array}$ \\
\hline 10 & 20.29 & 20.90 & 42.86 & 10.07 & 9.79 \\
20 & 16.45 & 17.04 & 36.15 & 7.39 & 7.15 \\
30 & 14.17 & 14.63 & 31.47 & 6.30 & 6.04 \\
40 & 12.28 & 12.74 & 26.78 & 5.57 & 5.29 \\
50 & 10.72 & 11.03 & 22.74 & 5.16 & 4.94 \\
60 & 9.38 & 9.59 & 18.99 & 4.95 & 4.78 \\
70 & 8.12 & 8.35 & 15.03 & 4.86 & 4.72 \\
80 & 7.04 & 7.15 & 11.72 & 4.82 & 4.73 \\
90 & 5.89 & 5.93 & 8.17 & 4.81 & 4.75 \\
100 & 4.83 & 4.83 & 4.83 & 4.83 & 4.83 \\
\hline & & & & &
\end{tabular}

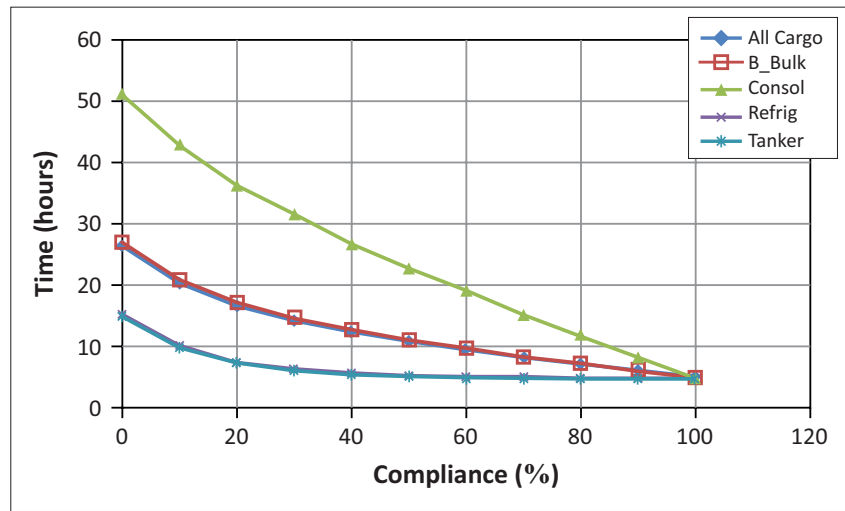

B_Bulk, break bulk cargo; Consol, consolidated cargo; Refrig, refrigerated cargo.

FIGURE 11: Graph showing the effect of implementing an RFID-enabled system on simulated border transit time for different cargo types at Beitbridge borde post. In this system, information exchange was possible throughout the trade corridor.
From Figure 12 it is clear that RFID-enabled systems provide a steady decrease in transit time, with the lowest value observed being 4.83 hours.

It should be noted from Tables 7-11 that for each scenario investigated, a different variable parameter was relevant (e.g. percentage pre-declarations or number of customs officials); in each case the transit times were calculated for 11 different values of the relevant variable parameter. In Figure 12, which compares transit times between the different scenarios, transit times are displayed for the 11 values used in each case; the $x$-axis therefore corresponds to different variable parameters as obtained from the respective tables.

\section{Discussion}

It is clear that the greatest reduction in transit time was obtained with the RFID-enabled system that allowed for continuous information exchange (RFID_SmartCapacity in Figure 12). Besides the exchange of information between customs and other stakeholders, this system also permitted the dynamic scheduling of processing capacity at customs based on the anticipated cargo arrival volumes. Across the different scenarios investigated, the average transit time reduced from 26.41 to 4.83 hours across all cargo types, which represents an efficiency improvement of about $82 \%$ compared to the status quo. The least reduction in transit time was obtained in scenario 2 , where only processing capacity at customs was changed. In this case, the transit time reduced from 26.41 to 17.10 hours. This represents a 35\% reduction in transit time. Other scenarios (see Figure 12) resulted in transit times between these two extremes.

These results are in line with the expected outcome. Changing processing capacity only at customs, without changing the processing capacities at other stations within the border post system, cannot cause substantially improved overall system performance. For example, once cargo has gone through customs clearance (Figure 1, block 8), it proceeds to the customs duty payment stage (Figure 1, block 9).

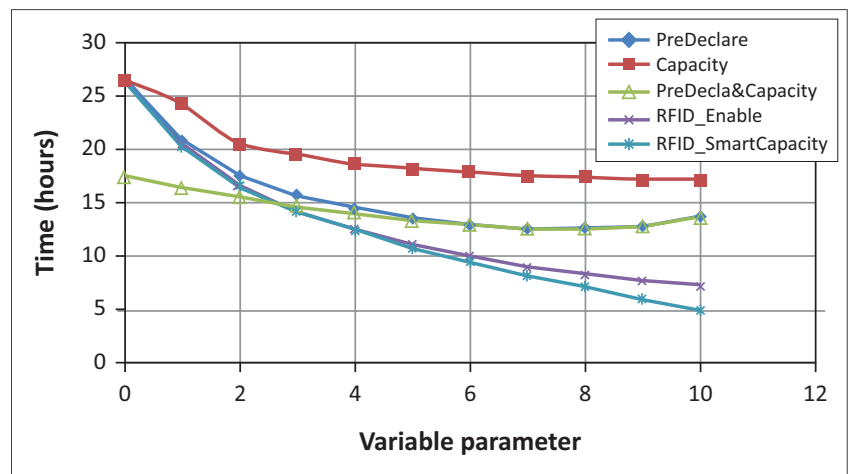

PreDeclare, pre-declaration varied; PreDecla\&Capacity, pre-declaration and capacity varied RFID_Enabled, radio-frequency identification enabled; RFID_SmartCapacity, radio-frequency identification enabled combined with adaptive information exchanged.

FIGURE 12: Comparison of simulated transit times achieved with various process changes across all cargo types. 
If the processing capacity at customs is increased without increasing capacity at the payment stage, more and more cargo will have to queue at the latter point. This erodes the gains of increasing customs processing capacity. In contrast, an RFID-enabled system supports data and information interchange between stakeholders and allows for dynamic and intelligent change in processing capacities at various stages. Furthermore, in the proposed system, many of the processing stages found in the present systems will be streamlined and most of the operations will be automated through the use of technology.

Literature pertaining to cross-border operations and associated delays, specifically in reference to developing countries, is limited. The work by Hsu et al. (2009) is closely related to the research described in this article, although it focused on improvement of customs processing of air cargo at an airport in Taiwan. Hsu et al. (2009) tested how the use of RFID systems would affect automating some of the operations. Their results indicated an improvement of about $63 \%$ with regard to performance and cost serving. Therefore, the results in this article are within range of the expected improvements as found in closely related literature.

The findings of our study may have far-reaching implications for stakeholders. For example:

- Governments will benefit from improved revenue collection as more cargo will be passing through the borders in a set period and there will be fewer opportunities for corruption.

- Exporters and importers will benefit from the improved turnaround time as they will be able to do more trips per month.

- Road agencies will spend less money on repairing roads if effective monitoring and controlling of overload are in place.

- Governments will need to restructure the infrastructure at the respective border posts in order to support the envisaged green lanes (improved system).

- Governments will need to revamp their customs processing software and risk engines to the modernised CREMS.

- Transporters will need to equip their trucks with GPSand RFID-supporting equipment.

- Cargo owners will need to acquire RFID equipment such as RFID readers, RFID tagging equipment and support for the electronic scanning of documents.

- Road agencies will need to acquire RFID readers and RFID software.

- Integration across the respective systems will be needed to facilitate the proposed information exchange.

For the envisaged system to be realised, a joint task force comprising government and other stakeholders should be formed. This task force will have to define measurable objectives and design a clear road map of each stakeholder's responsibilities.

\section{Conclusion and future work}

Regional initiatives to reduce transit time (Disenyana 2009; Nour, Siyengo \& Kidane 2011) by, for example, introducing OSBPs, have not produced the intended improvement (see Table 1, for the Chirundu border post). Long delays at the borders and the apparent failure of OSBPs have been attributed to human conduct (Curtis 2009; Fitzmaurice 2012). The simulation study reported on in this article has demonstrated that long delay times experienced at border posts can be eliminated by using a combination of information systems to enable information exchange between different stakeholders and modified operational processes. Our results show that the use of RFID-enabled systems can achieve an improvement of up to $82 \%$ with regard to average transit time for all cargo at a border post. The minimum average transit time for the improved system was found to be 4.83 hours; however, this may still be too high if Africa is to become competitive in international trade (Barka 2012; Norov \& Akbarov 2009).

In the present simulation model human conduct was not specifically included. However, in developing the simulation model, field data were heavily relied upon, in which the human element is presumed to have been inherently included. Further research is therefore proposed to:

- include human behaviour modelling in the model for trade corridors, including border posts (Schmidt 2002)

- determine compliance for arriving consignments not only from RFID checks at the point of origin of the route, but also by using GPS tracking data to verify compliance based on pre-agreed (geo-fenced) routes (Lusanga et al. 2014; Siror et al. 2010)

- include a reward system for drivers with a good road compliance record and for customs officials with the shortest processing time

- perform a cost-benefit analysis for each scenario to verify which of the scenarios will be able to pay for itself in the shortest time, taking into account the situation for each group of stakeholders

- complete development of an internet-enabled system that would allow transparency and visibility of cargo as it traverses the cross-border trade corridor(s) (Lusanga et al. 2014).

\section{Acknowledgements}

The authors express their gratitude to the reviewers of this article for their valuable input and constructive comments.

\section{Competing interests}

The authors declare that they have no financial or personal relationships that may have inappropriately influenced them in writing this article.

\section{Authors' contributions}

E.B. (University of KwaZulu-Natal) was responsible for developing the simulation model, running the simulation 
and compiling, analysing and presenting the results. E.B. was also responsible for writing the manuscript. A.H. (NorthWest University) was the project leader. K.L. (North-West University) and A.d.C. (North-West University) contributed to analysing historical data and final results.

\section{References}

Barka, H., 2012, 'Border posts, checkpoints and intra-Africa trade: Challenges and solutions', African Development Bank: OPEV Newsletter, January 2012, viewed 07 March 2015, from http://www.afdb.org/fileadmin/uploads/ afdb/Documents/Publications/INTRA\%20AFRICAN\%20TRADE INTRA\%20 AFRICAN\%20TRADE.pdf

Bhero, E. \& Hoffman, A., 2014, 'Optimizing border-post cargo clearance with auto-ID systems', Journal of Machine to Machine Communications 1, 17-30. http://dx.doi. org/10.13052/jmmc2246-137X.111

Curtis, B., 2009, 'The Chirundu border post: Detailed monitoring of transit time', report, Sub-Saharan Africa Transport Policy Program, 2009. http://www.ssatp. $\mathrm{org} / \mathrm{sites} / \mathrm{ssatp} /$ files/publications/SSATP-DiscussionPapers/DP10-Chirundu.pdf

Disenyana, T., 2009, 'Towards EAC, COMESA and SADC Free Trade Area', viewed 21 April 2013, from http://www.afdb.org/fileadmin/uploads/afdb/Documents/ Knowledge/2009\%20AEC- $\% 20$ Towards $\% 20$ an $\% 20$ EAC $\% 20$ COMESA $\% 20$ and $\% 20$ SADC $\% 2$ Free $\% 20$ Trade $\% 20$ Area $\% 20$ Issues $\% 20$ and $\% 2$ Challenges.pdf

Fitzmaurice, M., 2009, 'Optimization plan for freight movements at key commercial border crossings', report, Transport Logistics Consultants, Port Elizabeth.

Fitzmaurice, M., 2012, 'TLC report on Beitbridge, Chirundu, Kasumbalesa and Nakonde', report, Transport and Logistics Consultants, Port Elizabeth.

Globaltrack, 2015, 'Data service (online)', viewed 02 January 2015, from http://www. globaltrack.com

Hoffman, A., Lusanga, K. \& Bhero, E., 2013, 'A combined GPS/RFID system for improved cross-border management of freight consignments', paper presented at the Proceedings of AFRICON 2013, Pointe-aux-piments, Mauritius, 09-12 September.
Hsu, C., Shih, H. \& Wang, C., 2009, 'Applying RFID to reduce delay in import cargo customs clearance process', Computers and Industrial Engineering 57, 506-519. http://dx.doi.org/10.1016/j.cie.2008.02.003

Kelton, D., Smith, J. \& Sturrock, D., 2014, Simio and Simulation: Modeling, analysis and applications, 3rd edn., Simio LLC., Pennsylvania.

Laksmanan, T.R. \& Anderson, W.P., 2002, Freight services and economic growth: $A$ synopis of white paper, US Department of Transportation (Federal Highway Administration), Washington, DC.

Lusanga, P.K., Hoffman, A.J., De Coning, A. \& Bhero, E., 2014, 'A simulation strategy to optimize the design of internet enabled logistics services', paper presented at the 2014 IEEE 17th International Conference on Intelligent Transportation Systems, Qingdao, China, 08-11 October, pp. 2693-2699.

Mpata, S., 2011, 'Evaluation of the COMESA/SADC transit management systems: Final report', report, TradeMark Southern Africa, Lilongwe, viewed 07 March 2013 from http://www.trademarksa.org/sites/default/files/publications/Final\%20 Report $\% 20 \% 7$ C $\% 20$ Evaluation\%20of\%20the\%20COMESA:SADC\%20Transit\%20 Management\%20System.pdf

Norov, L. \& Akbarov, D., 2009, 'Customs - Time for a change', Problems of Economic Transition 52(2), 47-60. http://dx.doi.org/10.2753/PET1061-1991520203

Nour, Y., Siyengo, A. \& Kidane, Z., 2011, 'Mission report on COMESA-SADC coorporation on customs tansit management information system', report, TradeMark Southern Africa, viewed 21 April 2013, fom http://www.trademarksa. org/sites/default/files/publications/Mission $\% 20$ Report $\% 20 \% 7 \mathrm{C} \% 20$ COMESASADC $\% 20$ Cooperation $\% 200$ \% 20 Customs $\% 20$ Transit $\% 20$ Management $\% 20$ Information $\% 20$ System $\% 20 \% 7 C \% 20 F e b r u a r y \% 202011$.pdf

Schmidt, B., 2002, 'Modeling human behaviour: The PECS reference model', in A. Verbraeck \& W. Krug (eds.), Proceedings of the 14th European Simulation Symposium, n.p., Dresden, Germany, October 23-26.

Simio, 2013, Simio: Forward thinking, viewed 01 May 2013, from http://www.simio. com/index.php

Siror, J., Guangun, L., Kaifang, P., Huanye, S. \& Dong, W., 2010, 'Impact of RFID technology on tracking of export goods in Kenya', Journal of Convergence Information Technology 5, 190-199. http://dx.doi.org/10.4156/jcit.vol5.issue9.19

Thomas, V., Khadr, A. \& Girishankar, N. n.d., 'World Bank country-level engagement on governance and anticorruption', report, Independent Evaluation Group: World Bank, Washington, DC

Wegner, T., 2012, Applied business statistics, 3rd edn., Juta, Cape Town. 